\title{
Editorial: Adaptation of Trees to Climate Change: Mechanisms Behind Physiological and Ecological Resilience and Vulnerability
}

\author{
Andrea Ghirardo ${ }^{1 *}$, James D. Blande ${ }^{2}$, Nadine K. Ruehr ${ }^{3}$, Raffaella Balestrini ${ }^{4}$ and \\ Carsten Külheim ${ }^{5}$ \\ ${ }^{1}$ Research Unit Environmental Simulation, Institute of Biochemical Plant Pathology, Helmholtz Zentrum München, \\ Oberschleißheim, Germany, ${ }^{2}$ Department of Environmental and Biological Sciences, University of Eastern Finland, Kuopio, \\ Finland, ${ }^{3}$ Institute of Meteorology and Climate Research-Atmospheric Environmental Research, Karlsruhe Institute of \\ Technology KIT, Garmisch-Partenkirchen, Germany, ${ }^{4}$ Institute for Sustainable Plant Protection (IPSP)-National Research \\ Council (CNR), Turin, Italy, ${ }^{5}$ College of Forest Resources and Environmental Science, Michigan Technological University, \\ Houghton, MI, United States
}

Keywords: acclimation, adaptation, abiotic/biotic stress, climate-resilient tree, gene variation, plasticity, recovery, root-associated microbiota

\section{Editorial on the Research Topic}

\section{OPEN ACCESS}

Edited and reviewed by: Heather R. McCarthy, University of Oklahoma, United States

*Correspondence: Andrea Ghirardo

andrea.ghirardo@

helmholtz-muenchen.de

Specialty section

This article was submitted to

Forest Ecophysiology,

a section of the journal Frontiers in Forests and Global

Change

Received: 08 December 2021 Accepted: 30 December 2021

Published: 21 January 2022

Citation:

Ghirardo A, Blande JD, Ruehr NK, Balestrini R and Külheim C (2022)

Editorial: Adaptation of Trees to

Climate Change: Mechanisms Behind

Physiological and Ecological

Resilience and Vulnerability.

Front. For. Glob. Change 4:831701.

doi: 10.3389/ffgc.2021.831701
Adaptation of Trees to Climate Change: Mechanisms Behind Physiological and Ecological Resilience and Vulnerability

Climate change exposes plants to physiological conditions that are often outside their evolutionary limits (Shaw and Etterson, 2012). Multiple (a)biotic stressors such as heatwaves, drought, and insect/pathogen outbreaks are selective pressures on plant species and populations. However, the range of environmental conditions to which plants are adapted and their ability to acclimate to new conditions varies intra- and interspecifically. Plants can acclimate to stress by complex molecular and biochemical processes involving stress perception, signal transduction, gene expression, biochemical, physiological and morphological changes, and interactions with beneficial symbionts. Plant adaptation occurs through natural selection and ultimately relies on phenotypic plasticity, epigenetic modulations, and intraspecific genetic variation at individual and population levels.

This volume collected 11 articles, including primary research articles, opinions, and reviews that address fundamental questions and provide new insights into plant responses to climate change factors, focusing on biochemical and physiological adjustments underlying plant resilience and vulnerability.

Plant plasticity - the ability to change in response to stimuli or environments-can affect plant morphology and physiology by profound changes at molecular and metabolic levels. Alderotti et al. showed the anatomical, physiological, and biochemical responses triggered by a heatwave in Cistus incanus L., a shrub species adapted to hot and arid conditions typical of the Mediterranean basin. As an acclimation mechanism to heatwaves, the leaves had increased palisade parenchyma, resulting in a thicker lamina that enhanced resistance to dehydration and improved carbon assimilation. In addition, induction of secondary metabolites (tannins and terpenoids) indicated biochemical responses to counteract increasing oxidative stress. High plasticity is also characteristic of early successional species (Valladares et al., 2000). Carter et al. have studied in situ the effects of warming on photosynthesis and respiration of Psychotria brachiata and Piper glabrescens, which are early successional and mid-successional tropical shrubs. P. brachiata was able to acclimate the temperature optimum of photosynthesis $\left(\mathrm{T}_{\mathrm{opt}}\right)$, whereas $P$. glabrescens lowered stomatal 
conductance to decrease water loss resulting in lower photosynthesis. Shifts in $\mathrm{T}_{\mathrm{opt}}$ and rate of photosynthesis during acclimation to hot and dry environments can be explained by protein expression plasticity in the date palm (Phoenix dactylifera), a plant species well-adapted to xeric and hot environments (Kruse et al., 2019; Ghirardo et al., 2021). This highlights the importance of plasticity in acclimating to higher temperatures.

Plant resistance and resilience to drought stress are essential for plant survival. Xylem hydraulic failure is a ubiquitous factor in drought-driven tree-mortality. Drought-resistant species have meristematic cells with an enhanced ability to relocate stored water in tissues to avoid plasmolysis (Mantova et al., 2021). Schröter and Oberhuber reported that phloem is less susceptible to environmental influences, although knowledge on phloem adaptation to extreme climate conditions at the high-elevation treeline is scarce. Besides extreme conditions, global warming shifts precipitation and temperatures, extending the growing season and increasing the evapotranspiration of forest and cropland areas in Baltic countries (Montibeller et al.). At high latitudes, the warmer autumn seasons affect cold acclimationthe process that prepares evergreen conifers for the winter season. Noordermeer et al. found that low temperature is the dominant signal for the downregulation of photosynthesis and upregulation of photoprotection in cold acclimation of Douglas-fir. Autumn warming disrupts the key components of the autumn cold acclimation process, which is usually initiated by the shorter photoperiod and then triggered by sub-zero temperatures. Oksanen further reviewed the actual understanding of the responses and acclimation mechanisms of silver birch (Betula pendula) to changing environmental conditions. This deciduous tree species has high plasticity and is widely distributed in boreal forests, thus it has an excellent acclimation ability. The high genetic variation and the availability of genome data make silver birch a good model system for elucidating the adaptation mechanisms of northern trees to climate change.

Acclimation to stress can persist between generations toward adaptive transgenerational plasticity by epigenetics (Crisp et al., 2016). It relies on plant memory; the ability to remember a stress condition and respond faster and stronger upon subsequent stress. It also depends on the ability of plants to repair stress-induced damages (Ruehr et al., 2019). Li et al. showed that antecedent water limitation primes the responses and recovery dynamics of Eucalyptus camaldulensis upon subsequent drought stress, and the effects extend during post-stress recovery. Deciphering the role of stress legacy and memory on plant physiology and growth will be critical to foresee changes in plant community composition and function. However, understanding the ability of trees to adapt to climate change also requires knowledge of functional traits under selection. Directional selection-the natural selection that favors extreme phenotypes of a population-leads to great changes in allele frequencies in a population and increases the adaptiveness of plants. Costa e Silva et al., studied the population-level variation in functional traits of Eucalyptus pauciflora seedlings in dry and mesic sites and compared it to controlled experimental drought. Upon acute water limitation, the trait of lamina length exhibited a directional selection pattern in line with a shift in the mean of the mesic population toward that of the dry population. Therefore, past adaptation and gene variation reduce the plant's susceptibility to stress.

Root symbiosis with ectomycorrhizal and arbuscular mycorrhizal fungi can further mitigate the tree sensitivity to stress. Affnity for specific fungal symbionts is part of a tree's phenotype and may serve as a form of adaptation. Usman et al., reviewed the role of mycorrhizal symbioses in attenuating climate-driven increases in abiotic stresses. In general, the mechanisms in trees are similar to those found in non-woody plants and knowledge on the protective mechanisms gained on non-woody plants may help the manipulation of the tree microbiome to support the health and resilience of forests.

Biotic attacks often appear alongside climatic stresses, amplifying forest vulnerability. Therefore, large-scale monitoring of forest ecosystems is crucial for assessing forest health and tree mortality (Hartmann et al., 2018). Moreover, developing detection methods for tree diseases will be paramount to assist forest management. Antimicrobial peptides (AMPs) are a group of proteins of innate immunity mostly known in herbaceous plants. AMPs are secreted in the apoplastic space of peripheral cell layers and act in plant defense against pathogenic fungi, bacteria, viruses, and herbivores. To counteract the increasing spread of pathogenic infection, Nosenko et al. suggested using AMPs as markers for early detection of forest diseases. Yet, its development requires advanced knowledge of the AMPs-based defense mechanisms in woody plants. To prepare our forests for fighting climate change, Schroeder et al. proposed the selection of oak genotypes from natural forest stands based on molecular markers of single nucleotide polymorphisms. This strategy would enable the screening for resistant genotypes to (a)biotic stress while maintaining a rich gene pool. Resistant members of tree populations may be then used in seed orchards to assist climateresilient reforestation programs.

This Research Topic highlights the increasing number of studies addressing various aspects of woody plant adaptation, resilience, and vulnerability to climate change. There is a strong potential for adaptation under selective forces of climate change for plant species that have high variation in plasticity, genetics, trait expression and gene flow.

\section{AUTHOR CONTRIBUTIONS}

AG wrote the first editorial draft. All authors contributed to the article and approved the submitted version.

\section{FUNDING}

AG acknowledges the Fachagentur Nachwachsende Rohstoffe e. V. (FNR) in the programme Waldklimafond (28W-B-4-11301/2), funded by Federal Ministry of Food and Agriculture and Federal Ministry for Environment, Nature Conservation, and Nuclear Safety, Germany. NR was supported by the German 
Research Foundation through its Emmy Noether Program (RU 1657/2-1). RB acknowledges National Research Council (CNR) project FOE-2019 DBA.AD003.139. CK received financial

\section{REFERENCES}

Crisp, P. A., Ganguly, D., Eichten, S. R., Borevitz, J. O., and Pogson, B. J. (2016). Reconsidering plant memory: intersections between stress recovery, RNA turnover, and epigenetics. Sci. Adv. 2:e1501340. doi: 10.1126/sciadv.1501340

Ghirardo, A., Nosenko, T., Kreuzwieser, J., Winkler, J. B., Kruse, J., Albert, A., et al. (2021). Protein expression plasticity contributes to heat and drought tolerance of date palm. Oecologia 197, 903-919. doi: 10.1007/s00442-021-04907-w

Hartmann, H., Schuldt, B., Sanders, T. G. M., Macinnis-Ng, C., Boehmer, H. J., Allen, C. D., et al. (2018). Monitoring global tree mortality patterns and trends. Report from the VW symposium 'Crossing scales and disciplines to identify global trends of tree mortality as indicators of forest health.' New Phytol. 217, 984-987. doi: 10.1111/nph.14988

Kruse, J., Adams, M., Winkler, B., Ghirardo, A., Alfarraj, S., Kreuzwieser, J., et al. (2019). Optimization of photosynthesis and stomatal conductance in the date palm Phoenix dactylifera during acclimation to heat and drought. New Phytol. 223, 1973-1988. doi: 10.1111/nph.15923

Mantova, M., Herbette, S., Cochard, H., and Torres-Ruiz, J. M. (2021). Hydraulic failure and tree mortality: from correlation to causation. Trends Plant Sci. In press. doi: $10.1016 /$ j.tplants.2021.10.003

Ruehr, N. K., Grote, R., Mayr, S., and Arneth, A. (2019). Beyond the extreme: recovery of carbon and water relations in woody plants following heat and drought stress. Tree Physiol. 39, 1285-1299. doi: 10.1093/treephys/tpz032

Shaw, R. G., and Etterson, J. R. (2012). Rapid climate change and the rate of adaptation: insight from experimental quantitative support from a US Department of Agriculture, National Institute of Food and Agriculture, McIntire Stennis, Grant Accession Number 1017893. genetics. New Phytol. 195, 752-765. doi: 10.1111/j.1469-8137.2012.04 230.x

Valladares, F., Wright, S. J., Lasso, E., Kitajima, K., and Pearcy, R. W. (2000). Plastic phenotypic response to light of 16 congeneric shrubs from a panamanian rainforest. Ecology 81, 1925-1936. doi: 10.1890/0012-9658(2000)0811925:PPRTLO2.0.CO;2

Conflict of Interest: The authors declare that the research was conducted in the absence of any commercial or financial relationships that could be construed as a potential conflict of interest.

Publisher's Note: All claims expressed in this article are solely those of the authors and do not necessarily represent those of their affiliated organizations, or those of the publisher, the editors and the reviewers. Any product that may be evaluated in this article, or claim that may be made by its manufacturer, is not guaranteed or endorsed by the publisher.

Copyright $\odot 2022$ Ghirardo, Blande, Ruehr, Balestrini and Külheim. This is an open-access article distributed under the terms of the Creative Commons Attribution License (CC BY). The use, distribution or reproduction in other forums is permitted, provided the original author(s) and the copyright owner(s) are credited and that the original publication in this journal is cited, in accordance with accepted academic practice. No use, distribution or reproduction is permitted which does not comply with these terms. 